Lang, M. (2015) Touchy Subject: A Foucauldian Analysis of Coaches' Perceptions of Adult-Child Touch in Youth Swimming. Sociology of Sport Journal. 5. Available online ahead of print:

http://journals.humankinetics.com/ssj-in-press/ssj-in-press/touchy-subject-a-foucauldian-analysis-of-

coachesrsquo-perceptions-of-adult-child-touch-in-youth-swimming

\title{
Touchy Subject: A Foucauldian Analysis of Coaches' Perceptions of Adult-Child Touch in Youth Swimming
}

Melanie Lang

Senior Lecturer Child Protection in Sport

Edge Hill University, UK

\begin{abstract}
It has been suggested that child safety discourses are creating an environment in which safety from abuse defines every act of adult-child touch as suspicious, resulting in adults who work with children being positioned as 'risky' and child-related settings becoming no-touch zones. Research on the impact of these discourses on coaches is limited and there have been few attempts to theorize coaches' behaviours to better understand how child safety concerns impact on their practice. Focusing on coaches' avoidance of child touch, this paper uses a Foucauldian perspective to explore coaches' embodied disciplinary and emancipatory responses to child protection discourses in competitive youth swimming. It also discusses the implications of coaches' apprehension about child touch on swimming practice and young athletes.
\end{abstract}

\section{Keywords}

Adult-child touch, child abuse, Foucault, moral panic, youth swimming 
Lang, M. (2015) Touchy Subject: A Foucauldian Analysis of Coaches' Perceptions of Adult-Child Touch in Youth Swimming. Sociology of Sport Journal. 5. Available online ahead of print:

http://journals.humankinetics.com/ssj-in-press/ssj-in-press/touchy-subject-a-foucauldian-analysis-of-

coachesrsquo-perceptions-of-adult-child-touch-in-youth-swimming

\section{Introduction}

When Olympic swimming coach Paul Hickson was convicted in 1995 of the rape and sexual assaults of youth athletes in his care, the Amateur Swimming Association (ASA), swimming's governing body in England, embarked on a strategy aimed at protecting its youth swimmers. The ASA introduced one of the first child protection policies in sport (since updated, ASA, 2012) and began educating coaches about good practice and safeguarding children. Since then, research has identified the prevalence of abuse in various sports, including swimming (Fasting, Brackenridge, \& Sundgot-Borgen, 2004). In reaction, the United Kingdom (UK) has been placed at the vanguard of protecting children from abuse in sport: national governing bodies of sport (NGBs) are obliged to embed and disseminate child protection policies to receive state funding, coaches with regular contact with children must have a criminal background check and must attend child protection training, and the government has established an independent body, the Child Protection in Sport Unit (CPSU), to advise on safeguarding issues within sport (CPSU, 2003).

Simultaneously, young people have increasingly become the focus of a range of moral panics (Ungar, 2001). Anxiety surrounding risks to children such as obesity, falling educational standards, anti-social behaviour and child abuse, to name but a few, have increased (Ungar, 2001). According to Pain (2006), this epitomizes Beck's (1992) 'risk society', a new age of insecurity characterized by risk consciousness and risk avoidance. In particular, concern about the risk of child abuse, especially child sexual abuse and its unpredictable, invisible nature, has become a central fear of parents and legislators (Jones, Bailey, \& Santos, 2013; Pain, 2006) and, according to scholars, has escalated in Western societies to the status of a 
Lang, M. (2015) Touchy Subject: A Foucauldian Analysis of Coaches' Perceptions of Adult-Child Touch in Youth Swimming. Sociology of Sport Journal. 5. Available online ahead of print:

http://journals.humankinetics.com/ssj-in-press/ssj-in-press/touchy-subject-a-foucauldian-analysis-of-

coachesrsquo-perceptions-of-adult-child-touch-in-youth-swimming

'moral panic'. Faced with such an intangible threat, active trust (Beck, 1992) between individuals has gradually eroded, resulting in a lack of trust between adults when it comes to child safety (Furedi, 2001).

Anxiety about adult-child touch is one manifestation of this perceived threat to children.

Some argue this climate has created an environment in which safety from abuse defines every act of adult-child touch as suspicious, resulting in adults who work with children being positioned as potential abusers, with gendered constructions of child sexual abuse positioning men as the biggest threat to children (Marshall \& Mellon, 2011; Jones, Bailey, \& Santos, 2013). As with other perceived risks, the logical response is to manage the risk by implementing 'protective' policies including, in some cases, restrictive policies on adult-child interactions, including touch: "the central issues in world risk society is how to feign control over the uncontrollable" (Beck, 2002, p. 41). The result, it is argued, is that positive adultchild relationships are being damaged and child-related settings becoming no-touch zones (McWilliam \& Jones, 2005; Sikes \& Piper, 2011). It has been suggested that this has led to teaching and coaching becoming "conceptually and performatively unchallenged and [this has begun] to affect our capacities to think, act, feel and connect" (Pearce, 2010, p. 905).

In this risk world society, coaches, like other adults working in loco parentis, have become objects of distrust by other adults around them and increasing attention is being paid to adultchild interaction, both within and outside sport (Furedi, 2001). In sport, coaches have 
Lang, M. (2015) Touchy Subject: A Foucauldian Analysis of Coaches' Perceptions of Adult-Child Touch in Youth Swimming. Sociology of Sport Journal. 5. Available online ahead of print:

http://journals.humankinetics.com/ssj-in-press/ssj-in-press/touchy-subject-a-foucauldian-analysis-ofcoachesrsquo-perceptions-of-adult-child-touch-in-youth-swimming

identified athletes' parents, who often sacrifice elements of their own life and substantial amounts of time and money to drive their child's athletic success (Grenfell \& Rinehart, 2003), as their biggest source of concern (Lang, 2009), although in reality little is known about parents' views on coach-athlete touch.

In sport, most scholarly attention has focused on coaching transgressions from athletes' perspectives. After more than a decade of legislative and regulatory changes aimed at managing the risk to children in sport, little is known about the effect of these changes on coaches. How have coaches responded to child safety discursive regimes and to what extent do they engage in resisting practices? Given the dearth of research and particularly theoretical discussion on this topic in sport (notable exceptions being Lang, 2010 and Jones, Bailey, \& Santos, 2013), this paper draws on the tools of Michel Foucault to explore youth swimming coaches' responses to child safety discourses and situates this within the current discursive regime. In doing so, it identifies the extent to which coaches engage in transformative practices to have mastery over their own body.

Youth swimming was chosen as the locus of this inquiry for several reasons: swimming is one of the most popular participation sports among children and young people (Sport England, 2013), and the ASA has one of the most established safeguarding strategies of any UK NGB. Moreover, adult-child touch has a long tradition in swimming, for safety and reassurance purposes and to develop stroke techniques that comply with the laws of the sport. 
Lang, M. (2015) Touchy Subject: A Foucauldian Analysis of Coaches' Perceptions of Adult-Child Touch in Youth Swimming. Sociology of Sport Journal. 5. Available online ahead of print:

http://journals.humankinetics.com/ssj-in-press/ssj-in-press/touchy-subject-a-foucauldian-analysis-of-

coachesrsquo-perceptions-of-adult-child-touch-in-youth-swimming

This makes swimming a particularly interesting case study for understanding adult-child touch.

\section{The Politics of Touch in Youth Coaching}

Coaching is a holistic, social process involving "a constantly dynamic set of intra- and intergroup interpersonal relationships" (Cushion, 2007, p. 399). Understanding coaching in this way highlights the importance of coaches developing positive relationships with sport stakeholders, including athletes. It has been suggested that the relationship between coach and athlete is the most significant for it "is not an add-on to, or by-product of, the coaching process ... instead it is the foundation of coaching" (Jowett, 2005, p. 412).

In education, the benefits of a positive teacher-student relationship are well established (Murray \& Malmgren, 2005) and similar findings have been found in sport. A positive coachathlete relationship has been found to improve athletes' self confidence, satisfaction and enjoyment of sport (Jowett \& Cramer, 2010; Kidman \& Lombardo, 2010). Jones (2009) stresses how caring for athletes is central to both coaches' and athletes' success, while Potrac, Jones, \& Armour (2002) found that coaches consider strong social and personal bonds with athletes central to improving coaching practice and athletes' performance and overall development, not just as athletes but as people. Similarly, athletes have been found to prefer coaches who develop warm interpersonal relations with team members (Martin, Dale, \& Jackson, 2001). 
Lang, M. (2015) Touchy Subject: A Foucauldian Analysis of Coaches' Perceptions of Adult-Child Touch in Youth Swimming. Sociology of Sport Journal. 5. Available online ahead of print:

http://journals.humankinetics.com/ssj-in-press/ssj-in-press/touchy-subject-a-foucauldian-analysis-of-

coachesrsquo-perceptions-of-adult-child-touch-in-youth-swimming

Importantly, touch is crucial to the development of positive social and personal relationships (Field, 2003). Defined as "a class of nonverbal behaviour comprised of deliberate physical contact between two or more individuals" (Kneidinger, Maple, \& Tross, 2001, p. 44), touch is one of the most basic but powerful forms of communication. It can communicate feelings of approval, reassurance and security; reduce stress and anxiety; affirm relationships; and provide physical and psychological support, contributing to the fostering of warm, caring interpersonal cultures (Field, 2003; Hewitt, 2010).

Positive touch is also recognized as a useful and effective pedagogic tool for sports coaching (Andrzejewski \& Davis, 2008) because of the benefits discussed above and because, in many aspects of coaching, touch is necessary to demonstrate effective technique to athletes.

However, in a risk society so focused on adults' potential to harm children, touch has mutated from an acceptable way of demonstrating warmth and instruction to a signal of dangerous intent, predominantly in relation to sexual abuse (Piper \& Stronbach, 2008). In other words, all forms of touch have become conflated with abusive touch:

'no touch' is becoming, either intentionally or unintentionally, the most practical way of minimising risk to the individual teacher, regardless of whether is it pedagogically appropriate or desirable. (McWilliam \& Sachs, 2004, p. 21)

The ASA and British Swimming, the UK NGB, acknowledge that the current climate of fear surrounding adult-child interactions has rendered even pedagogic touch problematic. British Swimming (n.d., p. 2) suggests that "competent swimming teachers and coaches should be 
Lang, M. (2015) Touchy Subject: A Foucauldian Analysis of Coaches' Perceptions of Adult-Child Touch in Youth Swimming. Sociology of Sport Journal. 5. Available online ahead of print:

http://journals.humankinetics.com/ssj-in-press/ssj-in-press/touchy-subject-a-foucauldian-analysis-ofcoachesrsquo-perceptions-of-adult-child-touch-in-youth-swimming

friendly, tactile and approachable" but that coach-athlete physical contact is "fraught with difficulties" and places the teacher-coach "at undue risk." Consequently, while instructional touch is not prohibited, it suggests it is used with "the utmost care" (British Swimming, n.d., p.2) - in effect providing adults with "more stringent notions of 'acceptable risk"

(McWilliam \& Sachs, 2004, p. 20). This is worrying given that experiences of positive touch may make it easier for children to recognize inappropriate touch (Hewitt, 2010).

As noted earlier, it has also been suggested that a culture in which all adults are positioned as potential abusers is impacting negatively on coaches' interactions with athletes, and that coaches feel "constrained by the ever increasing climate of moral 'righteousness' not to [touch]" (Jones, Bailey, \& Santos, 2013, p. 10). Studies suggest that coaches, especially males, are becoming more cautious in their practice for fear of being accused of (sexual) abuse (Marshall \& Mellon, 2011; Piper, Taylor, \& Garrett, 2012) - concerns that are based more on abstract, discursive experiences than on personal experience given that the rate of false accusations is low (Brackenridge, Bringer, \& Bishopp, 2005). In addition, it is suggested that interpretations of child protection regulations are increasingly driven by desires for self-protection among adults (Marshall \& Mellon, 2011), which is understandable given the potentially devastating implications of an allegation even if it is later proved to be false.

Nonetheless, while adult-child touch can be a useful pedagogic tool and an innocent facilitator of positive social and personal relationships, it can also be used to physically abuse and, crucially given current Western social anxiety about child sexual abuse, to de-sensitize 
Lang, M. (2015) Touchy Subject: A Foucauldian Analysis of Coaches' Perceptions of Adult-Child Touch in Youth Swimming. Sociology of Sport Journal. 5. Available online ahead of print:

http://journals.humankinetics.com/ssj-in-press/ssj-in-press/touchy-subject-a-foucauldian-analysis-of-

coachesrsquo-perceptions-of-adult-child-touch-in-youth-swimming

children to sexual abuse as part of the grooming process. Child sexual abusers have been found to subtly increase adult-child touch through the use of touching 'games' or 'accidental' touch that progressively becomes more sexual to blur the boundaries of 'normal' behaviour and evaluate whether a child has been groomed sufficiently for abuse to begin (McAlinden, 2006). It is important, therefore, to differentiate between positive and negative touch. Positive touch behaviours include touch that can help develop positive social and personal relationships, which can be called 'caring touch,' and touch that has as its aim instruction, or 'instructional touch'. Meanwhile negative touch behaviours include physical abuse and touch aimed at grooming or otherwise abusing an individual, or 'abusive touch'.

\section{Theoretical Framework}

\section{Foucault's Discursive Knowledge and the Micro Workings of Power}

Foucault (1977a) theorized that the body is a subject of technologies of power. Opposing conventional conceptualizations of power as a 'thing' possessed by certain individuals or groups and wielded over others, Foucault argues that individuals are enmeshed in a web of power created by discourse, which operates within the daily exchanges between individuals, groups and institutions (Foucault, 1977a). As such, power is bound to the production of knowledge and the ability to define what is accepted as 'truth'. For Foucault, then, the body is created by and exists in discourse, resulting in power-knowledge inscribing itself on a subject's body: 
Lang, M. (2015) Touchy Subject: A Foucauldian Analysis of Coaches' Perceptions of Adult-Child Touch in Youth Swimming. Sociology of Sport Journal. 5. Available online ahead of print:

http://journals.humankinetics.com/ssj-in-press/ssj-in-press/touchy-subject-a-foucauldian-analysis-ofcoachesrsquo-perceptions-of-adult-child-touch-in-youth-swimming

The body is also directly involved in a political field; power relations have an immediate hold upon it; they invest it, mark it, train it, torture it, force it to carry out tasks, to perform ceremonies, to emit signs.

(Foucault, 1977a, p.25)

It is this understanding of the body and embodiment, wherein the body is identified as a construction inscribed with social meaning in and through discourse, that is adopted throughout this paper.

As with all forms of knowledge, current uncertainty and anxiety around adult-child touch is a constant shifting line in the sand, subject to whatever knowledge dominates at any one time. Understandings of adult-child touch as risky are recent (Piper, Taylor, \& Garrett, 2012) discursive constructions that provoke a physical, visceral embodied response, and create 'docile' coaches who come to internalize and enact societal demands for 'safe' or 'no-touch' practices. Indeed, the focus on the body and the micro workings of power means a Foucauldian analysis may help examine an exploration of touch as touch involves action and contact of the body (Kneidinger, Maple, \& Tross, 2001). Foucault's recognition of the body as a crucial site for the workings of power - a site where "knowledge formations and systems of power regulate corporal practices" (Rail \& Harvey, 1995, p. 165) - also provides a way to frame the effects of child safety discourses on the bodies of coaches. 
Lang, M. (2015) Touchy Subject: A Foucauldian Analysis of Coaches' Perceptions of Adult-Child Touch in Youth Swimming. Sociology of Sport Journal. 5. Available online ahead of print:

http://journals.humankinetics.com/ssj-in-press/ssj-in-press/touchy-subject-a-foucauldian-analysis-of-

coachesrsquo-perceptions-of-adult-child-touch-in-youth-swimming

Meanwhile, coaching is similarly discursively constructed, underpinned by various

knowledges from, among others, physiology, bio-mechanics, medicine, nutrition, psychology

(Denison \& Scott-Thomas, 2011). In this way, knowledge that comes to be identified as 'true'

- régimes of truth (Foucault, 1977a) that shape our understanding of ourselves and others

(Svender, Larsson, \& Redelius, 2012) - is not 'natural' but produced, governed by particular rules, inclusions and exclusions, in and through the power-knowledge nexus. Research has identified how technologies of dominance, in particular surveillance and self-surveillance, exert a "micro-physics of power" (Foucault, 1977a, p. 28) over the sporting body through the architecture, organisation and practices of sport, producing compliant and productive athletic bodies (Barker-Ruchti \& Tinning, 2010; Johns \& Johns, 2000; Lang, 2010; Markula, 1995). However, the focus of these analyses has predominantly been athletes who have been largely positioned as immutable subjects of dominant discourses and normalizing practices with limited capacity for agency. Less attention has been paid to coaches. Yet coaches, like athletes, are subject to discursive understandings of the 'correct' and 'incorrect' way to interact with youth swimmers. Equally, coaches are subject to disciplinary power - techniques of dominance, such as surveillance from athletes' parents, coaches and swimming authorities, encourage adherence to normative behaviours and coaches learn to become the subject of their own surveillance through engagement in self-disciplinary practices such as monitoring their own behaviour (Lang, 2010). In this way, a Foucauldian approach makes apparent how power exerts itself on the body, investing it with meaning and training its behaviour, providing a way to frame the effects of, for example, coach education courses and swimming training regimes and the discourses that underpin them on the bodies of coaches (Shogan, 1999). For example, through coaching qualification and Continuing Professional 
Lang, M. (2015) Touchy Subject: A Foucauldian Analysis of Coaches' Perceptions of Adult-Child Touch in Youth Swimming. Sociology of Sport Journal. 5. Available online ahead of print:

http://journals.humankinetics.com/ssj-in-press/ssj-in-press/touchy-subject-a-foucauldian-analysis-ofcoachesrsquo-perceptions-of-adult-child-touch-in-youth-swimming

Development (CPD) courses, coaches learn, internalize and construct normative values and behaviours, producing a certain kind of coach - homogenous, disciplined and versed in certain forms of knowledge but not in others (Lang, 2009).

A Foucauldian approach makes it possible to examine how bodies of knowledge, in this case knowledge about risk and child safety, produce "practices that systematically form the objects to which they speak" (Foucault, 1977b, p. 49), that is to say how child safety discourses shape coaches' behaviours.

In addition, Foucault (1988a, p. 12) recognized power as potentially enabling and transformative rather than simply limiting and repressive:

in the relations of power, there is necessarily the possibility of resistance for if there were no possibility of resistance ... there would be no relations of power.

(Foucault, 1988a, p. 12)

This understanding of power can be used to illuminate how everyday bodily practices have the potential to be used by individuals to transform power relations in sport. For the purposes of this study, a Foucauldian approach can provide nuanced insights into how discourse works to create 'docile' coaches who embody and internalize societal demands for 'safe' or 'notouch' practices and, simultaneously, how discourse allows coaches to actively resist current 
Lang, M. (2015) Touchy Subject: A Foucauldian Analysis of Coaches' Perceptions of Adult-Child Touch in Youth Swimming. Sociology of Sport Journal. 5. Available online ahead of print:

http://journals.humankinetics.com/ssj-in-press/ssj-in-press/touchy-subject-a-foucauldian-analysis-of-

coachesrsquo-perceptions-of-adult-child-touch-in-youth-swimming

relations of power and re-create themselves in opposition to dominant discourses. In adopting this approach, this paper hopes to explain how coaches' respond to child safety discourses and, crucially, why in order to bring about suggestions for change.

\section{Technologies of the Self and Opportunities for Transformation}

Foucault's theory of technologies of the self provides an important framework for understanding experiences that lead to practices within power relations of discourse but are not strictly confined by dominant discourses (Foucault, 1988a, 1988b). While Foucault recognized that technologies of the self can be used to transform power relations, he warned that this does not automatically lead to 'practices of freedom' (Foucault, 1983). Rather, a technology of the self becomes a practice of freedom only when a three-tiered process occurs, involving: (1) critical awareness; (2) self-stylization; and (3) ethical care of the self (Foucault, 1988b; Markula \& Pringle, 2006). Individuals must first problematize the discourses in which they exist, then a process of self-stylization can occur where an individual deliberately creates a self within that awareness of discourse and, through this, the individual can develop practices of transformation (Markula \& Pringle, 2006). Within the context of the current study, the problematization of child safety discourses would count as critical awareness. Yet for a practice of transformation to take place, coaches would also need to deliberately create a self within this awareness that was in opposition to dominant norms. The ability to think critically within discourse is central to Foucault's understanding of technologies of the self and the potential to transform power relations. It is a deliberate and conscious act in which 
Lang, M. (2015) Touchy Subject: A Foucauldian Analysis of Coaches' Perceptions of Adult-Child Touch in Youth Swimming. Sociology of Sport Journal. 5. Available online ahead of print:

http://journals.humankinetics.com/ssj-in-press/ssj-in-press/touchy-subject-a-foucauldian-analysis-of-

coachesrsquo-perceptions-of-adult-child-touch-in-youth-swimming

the individual becomes aware that what is considered normal is conditional rather than substantive (Markula \& Pringle, 2006).

While some scholars have drawn on Foucault's theory of technologies of the self to identify how sporting practices can be transformative rather than transgressive, explorations of how individuals re-create themselves through technologies of freedom in opposition to dominant discourses in sport are limited (e.g. Chapman, 1997; Johns \& Johns, 2000; Markula, 2004). Of these, however, some that claim to demonstrate athletic individuals engaging in practices of freedom provide only limited evidence that athletes are doing so in opposition to the discursive practices of their sport in the way that is required to take steps towards practices of freedom (e.g. Chapman, 1997; Johns \& Johns, 2000). As Markula (2003, p. 104) notes, scholars have interpreted practices of freedom differently in part because "there is no clear formula that will detect which sporting practices serve as practices of freedom", partly because Foucault died before fully completing this section of his work. What is clear from Foucault's work, however, is that active problematization of dominant discursive constructions and self-stylization in response to this are crucial to deciding whether or not an act qualifies as a practice of freedom (Foucault, 1984). Indeed, Foucault argued that it was necessary to analyse "not behaviours or ideas, nor societies and their 'ideologies', but the problematizations through which being offers itself to be, necessarily, thought - and the practices on the basis of which these problematizations are formed" (Foucault, 1984, p. 11, original emphasis). It is this understanding, as proposed by Foucault and used by Markula 
Lang, M. (2015) Touchy Subject: A Foucauldian Analysis of Coaches' Perceptions of Adult-Child Touch in Youth Swimming. Sociology of Sport Journal. 5. Available online ahead of print:

http://journals.humankinetics.com/ssj-in-press/ssj-in-press/touchy-subject-a-foucauldian-analysis-of-

coachesrsquo-perceptions-of-adult-child-touch-in-youth-swimming

(2004) and Markula \& Pringle (2006), that underpins the discussion of practices of freedom in this paper.

A decade after Markula (2003) called on sociologists to engage with Foucault's theory of technologies of the self, this paper contributes to this area of scholarship by exploring the extent to which youth swimming coaches create a transformative self within the discursive regime in which they exist.

\section{Methods}

The study explored youth swimming coaches' perceptions of coach-athlete touch and how they enact this when coaching. The research was approved by the author's university ethics committee and all clubs and participants were guaranteed anonymity; pseudonyms are used throughout this paper. An ethnographic design was adopted to capture the depth and breadth of coaches' feelings and actions regarding coach-athlete touch and to enable a more thorough exploration of the discursive resources that coaches have access to and are shaped by. Indeed, ethnography was employed in this study because it is:

concerned with what people are, how they behave, how they interact together. It aims to uncover their beliefs, values, perspectives, motivations and how all these things develop or change over time or from situation to situation. It tries to do all this from within the group, and from within the perspectives of the group's members.

(Woods, 1986, p. 4; original emphasis) 
Lang, M. (2015) Touchy Subject: A Foucauldian Analysis of Coaches' Perceptions of Adult-Child Touch in Youth Swimming. Sociology of Sport Journal. 5. Available online ahead of print:

http://journals.humankinetics.com/ssj-in-press/ssj-in-press/touchy-subject-a-foucauldian-analysis-of-

coachesrsquo-perceptions-of-adult-child-touch-in-youth-swimming

Initial data were gathered through ethnographic observations of, and informal conversations with, 13 coaches at three ASA-affiliated clubs in north England to triangulate data collection by working in different settings (Lincoln \& Guba, 1985). As a former elite swimmer, I swam as a youth for two clubs in this region in the 1980s-1990s and, in my 20s and 30s, taught beginner swimming lessons at these and other clubs. At the time of the research I was also a national-level competitive Masters swimmer at a club in the region. My involvement in the sport meant I knew many coaches and other stakeholders in the region who acted as brokers to facilitate my introduction to the coaches in the study. My background also afforded me what McNeill (1988) calls an ‘insider identity’ within swimming culture and proved crucial in negotiating access to clubs with coaches; all coaches commented on my swimming background with several noting this was "very useful for the club" (field notes, 30/07/07 and 06/12/07). In addition, my 'insider' knowledge of swimming culture helped me plan what, when and how to observe coaches and, when analysing the data, helped me interpret and understand the coaches' behaviour and its relationship to the context of youth swimming culture (Maykut \& Morehouse, 1994); I was, in Maykut and Morehouse's (1994, p. 123) words, "tuned-in to the experiences and meaning systems of [swimming]". In this sense, the conclusions drawn here, while underpinned by the data gathered and supported by member checking from coaches, are, in part, informed by my previous experiences both as a swimmer and as a swimming teacher and coach.

Observations took place over a 12-month period. Participants were 22-60-years-old and four were women. Observations took place in blocks of several hours, beginning shortly before training began and running until after sessions had ended to allow observation of athletes' 
Lang, M. (2015) Touchy Subject: A Foucauldian Analysis of Coaches' Perceptions of Adult-Child Touch in Youth Swimming. Sociology of Sport Journal. 5. Available online ahead of print:

http://journals.humankinetics.com/ssj-in-press/ssj-in-press/touchy-subject-a-foucauldian-analysis-ofcoachesrsquo-perceptions-of-adult-child-touch-in-youth-swimming

and coaches' interactions on the poolside. Most observations were of pool sessions, although land-based training and competitions also were observed at two clubs. Data were generated via written and verbal field 'notes' that documented observed behaviour and informal discussions. Where possible, these notes were written but I also took lengthier audio 'notes' as memory prompts for later transcription in my field diary. All coaches accepted my request to observe from the poolside - no doubt a benefit of my 'insider status' and a necessity in large, echoing pools. Initially, my role was similar to Willis' (1980) description of the ethnographer simply 'being around'. However, at each club I was gradually encouraged to play a more active role - mostly clearing equipment from the poolside at the end of sessions, but on two occasions I was asked to lead sessions while coaches ran errands. At one club I was even asked to participate in a training session. These moves were, I felt, orchestrated to 'test' my 'insider status' and which, once passed, led to friendlier relations with coaches.

Observations were followed by semi-structured interviews with coaches. Eleven of the 13 coaches involved in observations were interviewed; one declined and one left the club during the fieldwork. Interviews drew on past literature and observational data. Themes included participants' perceptions of child protection, its impact on their coaching and coach-athlete interactions. Interviews lasted between 50 and 120 minutes and were recorded with the coaches' permission. The findings presented here draw on both observational and interview data.

\section{Data Analysis}


Lang, M. (2015) Touchy Subject: A Foucauldian Analysis of Coaches' Perceptions of Adult-Child Touch in Youth Swimming. Sociology of Sport Journal. 5. Available online ahead of print:

http://journals.humankinetics.com/ssj-in-press/ssj-in-press/touchy-subject-a-foucauldian-analysis-of-

coachesrsquo-perceptions-of-adult-child-touch-in-youth-swimming

Data analysis was on-going and began during the observations. Field notes were typed up and interviews transcribed before being subject to inductive analysis to allow findings to emerge from the dominant themes inherent in them (Goetz \& LeCompte, 1984). This involved reading and re-reading the text to become immersed in "the details and specifics of the data to discover important patterns, themes, and interrelationships" (Johnson \& Christensen, 2004, p. 362). Simultaneously, segments of text were coded into emergent themes to facilitate analysis of text based on specific themes and to enable relationships between themes to be identified, including contradictory points and new categories. To help explain the themes arising, analytical memos were also used to note "preliminary and tentative connections to various theoretical concepts" (Sparkes, 2000, p. 18). Through this process themes became increasingly refined, finally resulting in themes discussed in this paper. Finally, following Lincoln and Guba (1985), anonymized transcripts and analytical interpretations of these were sent to participants as part of the process of establishing trustworthiness and to encourage reflexive elaboration (Sparkes, 1989).

\section{Findings and Discussion}

\section{Coaches' Embodied Response to Child Safety Discourses}

Consciousness of child safety discourses that position adults working with children as suspicious, in particular discourses that conflate negative (abusive) touch with positive (caring and instructional) touch, provoked a physical response among coaches - they regulated their touching behaviour with youth athletes. Where possible, this involved avoidance of adult-child touch. For example, coaches were observed avoiding instructional 
Lang, M. (2015) Touchy Subject: A Foucauldian Analysis of Coaches' Perceptions of Adult-Child Touch in Youth Swimming. Sociology of Sport Journal. 5. Available online ahead of print:

http://journals.humankinetics.com/ssj-in-press/ssj-in-press/touchy-subject-a-foucauldian-analysis-of-

coachesrsquo-perceptions-of-adult-child-touch-in-youth-swimming

touch by only touching athletes with floats when illustrating hand positioning and calling swimmers' parents onto the poolside so they could manipulate their child's limbs. Coaches also regularly engaged in 'air touching,' reaching out towards swimmers to get their attention but stopping short of touching them. Similarly, coaches talked about avoiding engaging in other forms of positive touch with youth swimmers:

We clearly try not to touch them these days, 'erm, and that's very difficult at times particularly when you get some children who complain of cramp or whatever and you just have to show them, you know, you have to massage your own bones and your own leg to show them how to do it. (Dave)

Several coaches also discussed how they were trying to discourage athletes from caring touch, such as when congratulating or commiserating with coaches:

Sometimes if a swimmer's done well, some swimmers have come up to me and tried to give me a hug and you're like 'wooaaah' ... You try and motivate them as much as you can, we're trying to get them to do high fives or even waves, it's more like that instead of hugs. (Jenny)

In situations where positive adult-child touch was unavoidable, such as when it was initiated by a swimmer, coaches attempted to limit their touch to specific parts of the child's and/or their own body. For example during observations of a competition at one club, a distraught 
Lang, M. (2015) Touchy Subject: A Foucauldian Analysis of Coaches' Perceptions of Adult-Child Touch in Youth Swimming. Sociology of Sport Journal. 5. Available online ahead of print:

http://journals.humankinetics.com/ssj-in-press/ssj-in-press/touchy-subject-a-foucauldian-analysis-of-

coachesrsquo-perceptions-of-adult-child-touch-in-youth-swimming

child who had been disqualified from her race attempted a commiseration hug with her coach, Jim:

The girl, who looked about 8 or 9, clamped her arms around Jim's waist, buried her head in his crotch and started crying. Jim looked uncomfortably towards the other coaches then wiggled around so he was sideways on to the girl, genitals pointing as far away from her face as was practically possible, and ruffled the girl's hair while saying, 'It doesn't matter, don't cry.' (Field notes)

Other coaches also engaged with this idea that the body is divided into acceptable and nonacceptable touch zones:

I think a big thing on child protection is, I know, you don't touch [a child] between the shoulders and the knees. (Amanda)

You make sure you touch them in the right place, you just touch their hand or their arm if you have to ... or the head. You don't go near the body. (John)

These coaches were aware that adult-child touch is often viewed by others through a prism of suspicion and, in reaction to the Panoptic gaze of numerous others - parents, other coaches, swimming authorities - they sought to restrict their touch practices. One way of doing this was by carving up the body - both the child's and their own - into sexual 'no-go' zones 
Lang, M. (2015) Touchy Subject: A Foucauldian Analysis of Coaches' Perceptions of Adult-Child Touch in Youth Swimming. Sociology of Sport Journal. 5. Available online ahead of print:

http://journals.humankinetics.com/ssj-in-press/ssj-in-press/touchy-subject-a-foucauldian-analysis-ofcoachesrsquo-perceptions-of-adult-child-touch-in-youth-swimming

(essentially, the torso) and non-sexual, more (though not completely) acceptable zones (everywhere else). This is echoed in swimming's guidelines on handling children, which recommend teachers and coaches, "Never support a pupil by handling the swimmer's torso" and "Only support swimmers by holding their hands, head or feet" (British Swimming, n.d., p. 2). In the same way that this fails to distinguish between positive and negative forms of touch so these coaches, intentionally and unintentionally, conflated positive caring and instructional forms of touch with abusive touch. Alternative discourses on touch as positive are marginalized at the expense of discourses of touch as negative and coaches, drip-fed on this 'hidden curriculum', learn to accept this state of affairs as the 'natural' or only 'order of things' (Foucault, 1970). Current child safety discourses that define even positive forms of adult-child touch as 'risky' have shaped coaches' understandings of 'correct' social conduct when working with youth athletes, becoming a 'régime of truth,' a 'prescriptive text ... that elaborate[s] rules, opinions and advice as to how to behave as one should" (Foucault, 1984, p. 12). Coaches, aware of their exposure to the watchful eye of others, internalize the Panoptic gaze and regulate their behaviours toward an accepted standard so that the soul becomes "the prison of the body" (Foucault, 1977a, p. 30). Consequently, they moulded themselves into restrained, distanced bodies that were disciplined via "a precise, prescribed physicality" (Jones, 2004, p. 61). In adopting this strict interpretation of appropriate risk through limiting touch behaviours, coaches missed the opportunity to develop positive relations with their athletes and were unable to take advantage of the pedagogic usefulness of touch (Andrzejewski \& Davis, 2008; Field, 2003; Hewitt, 2010).

\section{Self Protection}


Lang, M. (2015) Touchy Subject: A Foucauldian Analysis of Coaches' Perceptions of Adult-Child Touch in Youth Swimming. Sociology of Sport Journal. 5. Available online ahead of print:

http://journals.humankinetics.com/ssj-in-press/ssj-in-press/touchy-subject-a-foucauldian-analysis-of-

coachesrsquo-perceptions-of-adult-child-touch-in-youth-swimming

While this approach has the potential to negatively impact on the development of trusting, confident athletes with effective swimming stroke technique, the coaches rationalized this through a prism of self protection:

My main worry is being accused of something that you've not done, so the main thing is not being alone with a swimmer at any time so accusations can't be made. (Mike)

You don't ever get in a situation where it's just you and a swimmer and nobody else about because then you're opening yourself up to potential allegations ... It's important that if you're going to speak to children there's another coach or parents there ... Everyone's got to cover their backs. In that sort of situation you can't be seen to be, 'erm, flippant or lax. (Chris)

In a risk world society, these coaches understood themselves as both objects of distrust and of vulnerability, that is as 'risky' subjects (e.g. of risk to children) and, simultaneously, 'at risk' of being accused of abuse. Research into the level of unfounded allegations within sport is limited although one study, which used referrals to the Football Association, found that of 132 allegations only one, for physical abuse, was found to be false (Brackenridge, Bringer, \& Bishopp, 2005). Meanwhile, while some studies suggest an increase in unfounded allegations against teachers, the numbers remain small - most likely much smaller than the number of non-reported cases of abuse (Williams, 2004). Therefore, fear of an allegation of abuse is likely to be disproportionate to the actual rate of accusations, unfounded or otherwise (Brackenridge, Bringer, \& Bishopp, 2005); coaches' concerns are based more on emotions 
Lang, M. (2015) Touchy Subject: A Foucauldian Analysis of Coaches' Perceptions of Adult-Child Touch in Youth Swimming. Sociology of Sport Journal. 5. Available online ahead of print:

http://journals.humankinetics.com/ssj-in-press/ssj-in-press/touchy-subject-a-foucauldian-analysis-of-

coachesrsquo-perceptions-of-adult-child-touch-in-youth-swimming

and abstract, discursive experiences than on personal experience. These unwarranted concerns led coaches to prioritize self protection over child protection (Marshall \& Mellon, 2011), with coaches behaving in similar ways to adults in other child-related settings:

[They] avoid any contact, or when they did have contact, to dehumanise it, to avoid any touch or speech that might be misinterpreted, and to cling to rules like safety ropes on a stormy deck ... Common sense [goes] out the window - crowded out by fear and regulation, whether real or imagined. (Marshall \& Mellon, 2011, p. 192)

\section{Risk as a Gendered Phenomenon and Restricting Practice}

Awareness of discourses of risk was also gendered. Although coaches of both sexes identified themselves as vulnerable to accusations of abuse, several coaches engaged with dominant discourses of child safety that position men as more risky subjects than women (Marshall \& Mellon, 2011):

I think in the current climate as a woman you're more able to say and to do things unreservedly, whereas a man wouldn't be ... I think a man would be more likely to be accused of something if he shouted, 'erm, I don't know, whereas a woman wouldn't.

\section{(Sheila)}

I think it does make a difference being a man because you're a bit, 'erm, more under suspicion ... and people might question why you do it. (Kevin) 
Lang, M. (2015) Touchy Subject: A Foucauldian Analysis of Coaches' Perceptions of Adult-Child Touch in Youth Swimming. Sociology of Sport Journal. 5. Available online ahead of print:

http://journals.humankinetics.com/ssj-in-press/ssj-in-press/touchy-subject-a-foucauldian-analysis-ofcoachesrsquo-perceptions-of-adult-child-touch-in-youth-swimming

It has been suggested that males are considered more risky subjects that females and that, consequently, men are more likely to avoid touching others, particularly children (Jones, 2004). However, while the coaches in this study positioned men as representing more of a threat and, therefore, more subject to the risk of being accused of abuse, both male and female coaches reported feeling vulnerable to allegations. The growth in the number of women who position themselves as at risk of being accused of abuse has been noted elsewhere (McWilliam \& Jones, 2005). One explanation posited for this rise is that it is the outcome of women becoming "infected by professional association" with men working in the same field (Piper, Powell, \& Smith, 2006, p. 159). As coaching is a male-dominated profession (Sports Coach UK, 2011), this may explain why the women coaches in this study positioned themselves as equally at risk of being accused of abuse as their male counterparts.

The discourse of fear in which abusive touch is conflated with caring touch had a significant impact on many of the coaches, leaving them feeling angry and constrained:

[Child protection] concerns the News of the World, that's it ... I guess they had a problem with a couple of coaches, a couple of teachers and they decided it'd be better if all the kids suffer. It's ridiculous ... To say that ...you shouldn't really touch a child when you're teaching them to swim, I mean, you've got to. You've got to touch a child to help them ride a bike. [In swimming] you've got to touch them. You've got to say, 'You put your arm in there and you pull 
Lang, M. (2015) Touchy Subject: A Foucauldian Analysis of Coaches' Perceptions of Adult-Child Touch in Youth Swimming. Sociology of Sport Journal. 5. Available online ahead of print:

http://journals.humankinetics.com/ssj-in-press/ssj-in-press/touchy-subject-a-foucauldian-analysis-of-

coachesrsquo-perceptions-of-adult-child-touch-in-youth-swimming

it back to there' ... That contact is really important. It's absolutely critical. Yet we're not supposed to do that now. (Andrew)

My job is at times very physical where I have to get them out on poolside and I have to put them into positions and get them to grasp the feeling, 'erm, and ... I only feel like I can touch swimmers with kickboards and pull buoys to shape their hands into positions and I think that's very sad. (Steven)

These coaches felt "constrained by the ever increasing climate of moral 'righteousness' not to [touch]" (Jones, Bailey, \& Santos, 2013, p. 10) - a long way from the "friendly, tactile" coach British Swimming is hoping for (British Swimming, n.d., p. 2). Yet swimming coaches are not prohibited from touching athletes. Exploring why these coaches, against their better judgement, stayed faithful to the discursive regime is crucial if we are to understand this behaviour and offer insights into how to counter it.

\section{The Path to Practices of Freedom}

As noted above, swimming coaches are not prohibited from touching athletes. Equally, coaches are not passive products of child safety discourse, immutably bound to docility and anxiety about child touch. Coaches can, through a process of subjectification (Foucault, 1984, 1988a, 1988b), craft themselves into active subjects that reject dominant child safety discourses and result in alternative touch practices or 'practices of freedom' (Foucault, 1983). 
Lang, M. (2015) Touchy Subject: A Foucauldian Analysis of Coaches' Perceptions of Adult-Child Touch in Youth Swimming. Sociology of Sport Journal. 5. Available online ahead of print:

http://journals.humankinetics.com/ssj-in-press/ssj-in-press/touchy-subject-a-foucauldian-analysis-ofcoachesrsquo-perceptions-of-adult-child-touch-in-youth-swimming

However, the coaches in this study avoided engaging in practices that placed them in opposition to dominant constructions of adult-child touch as 'risky.' Dave explains why:

Well, well, no I don't think you should touch, 'erm ... it, erm, it makes it ... you know, easier to get up to no good, if you see what I mean, so erm, yes I don't have a problem with it. In theory you shouldn't need to touch them to show them a stroke. (Dave)

While several coaches expressed anger at constructions of adult-child touch as suspicious, most showed limited awareness that this was a discursive product, conditional rather than substantive in nature, and most did not problematize those discourses in the way that is required to take steps towards practices of freedom (Markula, 2003, 2004; Markula \& Pringle, 2006). Only one coach, Kevin, hinted that knowledge about adult-child touch as 'risky' is produced rather than natural. Nevertheless, he stopped short in his discussion and during observations of deliberately engaging in a process of self-stylization to create a self within that awareness of discourse (Markula \& Pringle, 2006):

Sometimes, 'erm, I think it might go a bit over the top with health and safety and the things you're not meant to do like hugging the kids and that, but with the guidelines I can see why it was done and ... I would say as a coach I'm going to follow them because it protects me. (Kevin) 
Lang, M. (2015) Touchy Subject: A Foucauldian Analysis of Coaches' Perceptions of Adult-Child Touch in Youth Swimming. Sociology of Sport Journal. 5. Available online ahead of print:

http://journals.humankinetics.com/ssj-in-press/ssj-in-press/touchy-subject-a-foucauldian-analysis-of-

coachesrsquo-perceptions-of-adult-child-touch-in-youth-swimming

For these coaches, the discursive regime of adults as potential abusers dominated alternative discourses around the importance of developing positive coach-athlete relations.

Consequently, the coaches adopted a worst-case scenario approach to protect themselves.

As Marshall and Mellon (2011) argue, adults cannot be entirely blamed for this. Discourses represent a "series of discontinuous segments whose tactical function is neither uniform nor stable" (Foucault, 1978, p. 100). Multiple discourses, then, exist alongside one another, with some dominating and other alternative discourses more marginalized. Within coaching, discourses surrounding the best way to develop swimmers' technique compete with discourses surrounding the most effective way to develop positive trusting relationships with athletes, which in turn compete alongside discourses of child safety. The dominance of certain discourses influences what can be known and simultaneously obscures other forms of knowledge, and this working of discourse creates seemingly natural régimes of truth that guide the way individuals understand what is true, the way they see themselves and how they behave (Foucault, 1988a). In this case, discourses of child safety that position adults as potential abusers have become a régime of truth for coaches, trumping alternative discourses, shaping their perception of self and moulding their behaviour so they become 'docile' adherents of the 'no-touch' regime (McWilliam \& Sachs, 2004).

\section{Conclusion}

Drawing on the theoretical tools of Michel Foucault, this paper identified how youth swimming coaches have responded to child safety discourses within a risk society. In 
Lang, M. (2015) Touchy Subject: A Foucauldian Analysis of Coaches' Perceptions of Adult-Child Touch in Youth Swimming. Sociology of Sport Journal. 5. Available online ahead of print:

http://journals.humankinetics.com/ssj-in-press/ssj-in-press/touchy-subject-a-foucauldian-analysis-ofcoachesrsquo-perceptions-of-adult-child-touch-in-youth-swimming

particular, it identified how a régime of truth emanating from current child safety discourses works to create 'docile' swimming coaches who come to embody and internalize societal demands for 'safe' or 'no-touch' practices. Discursive constructions that position adults who work with children as potential child abusers have created the 'knowledge' among coaches that they are under constant suspicion of being an abuser. As a result, a régime of truth surrounding what it means to be a 'safe' coach has emerged, with avoidance of adult-child touch as the central principle. Indeed, these findings suggest that coaches conflated positive touch with negative touch and also limited their use of all forms of adult-child touch, even positive forms, as a way of managing the risk of being accused of abuse. If this was not possible, they limited their touch to areas of the body considered less 'risky', a process usually described in negative terms because of its impact on coaches' ability to develop positive coach-athlete relationships.

This paper also identified the extent to which these coaches engaged with resisting practices to begin to transform their experiences. Most of the coaches did not problematize discursive understandings of adult-child touch as 'risky' and those that did were unwilling or unable to engage in a process of self-stylization that is required to constitute a technology of the self (Foucault, 1983, 1984, 1988b; Markula, 2003, 2004; Markula \& Pringle, 2006). For these coaches, concern about being accused of abuse had become a régime of truth so strong that it that eradicated alternative understandings of coach-athlete interactions. 
Lang, M. (2015) Touchy Subject: A Foucauldian Analysis of Coaches' Perceptions of Adult-Child Touch in Youth Swimming. Sociology of Sport Journal. 5. Available online ahead of print:

http://journals.humankinetics.com/ssj-in-press/ssj-in-press/touchy-subject-a-foucauldian-analysis-of-

coachesrsquo-perceptions-of-adult-child-touch-in-youth-swimming

In this regard, the work of Foucault provided a greater conceptual understanding of coaches' thoughts and behaviours in relation to the discursive regime in which they exist. Research on this topic to date has tended to describe coaches' actions without explanation other than to point the finger of blame at 'restrictive' child protection regulations. But the blame game is rarely helpful. Researchers (and coaches and coach educators) must not (re)produce such constructions if we are to avoid exacerbating the current moral panic about child (sexual) abuse and instead encourage the development of positive touch. Future discussions of positive touch would benefit from considering the usefulness of this approach.

Coaches who avoid using positive touch in their coaching risk being unable to communicate effective swimming technique to their athletes and missing the opportunity to foster positive interpersonal relationships with the young people for whom they give up so much time. Meanwhile for athletes, the potential lack of warmth in the relationship with their coach could impact on their involvement in the sport and a dearth of experience of extra-familial positive touch may make it more difficult for them to recognize inappropriate touch (Hewitt, 2010). Given the usefulness of touch as a pedagogic tool (Andrzejewski \& Davis, 2008) and given that caring touch can communicate emotional and psychological support (Field, 2003; Hewitt, 2010), coaches should be encouraged to problematize constructions of adult-child touch as risky. For example, following Foucault's (1988a) theory of circulating marginalized knowledges, evocative collective narratives illustrating alternative discourses on adult-child interactions, could be included in coach education, with attendees invited to reflect on these in an attempt to kick start critical problematization. Finally, more research that explores and 
Lang, M. (2015) Touchy Subject: A Foucauldian Analysis of Coaches' Perceptions of Adult-Child Touch in Youth Swimming. Sociology of Sport Journal. 5. Available online ahead of print:

http://journals.humankinetics.com/ssj-in-press/ssj-in-press/touchy-subject-a-foucauldian-analysis-of-

coachesrsquo-perceptions-of-adult-child-touch-in-youth-swimming

theorizes the boundaries of coaches' touch practices in other sports is also needed, as are studies that investigate athletes' and parents' perspectives on positive adult-child touch.

\section{Acknowledgements}

I would like to thank the editor and the two anonymous reviewers for their thoughtful and insightful comments on earlier versions of this paper.

Notes

${ }^{1}$ Sir Jimmy Savile was a British TV presenter, charity fundraiser and celebrity, and is now considered “one of the UK's most prolific known sexual predators" (Gray \& Watt, 2013, p. 24). In 2012, the police launched an investigation into historic abuse by the star following the broadcast of a programme alleging sexual abuse and rape by Savile in the 1970s. Savile is suspected of offences against some 450 children and adults between 1955 and 2009. Savile died in 2011 so cannot be prosecuted.

\section{References}

Amateur Swimming Association (ASA) Wavepower 2012/15: The ASA child safeguarding policy and procedures. Loughborough, ASA. Available at: www.swimming.org/asa/clubsand-members/safeguarding-children. Accessed 19/6/13. 
Lang, M. (2015) Touchy Subject: A Foucauldian Analysis of Coaches' Perceptions of Adult-Child Touch in Youth Swimming. Sociology of Sport Journal. 5. Available online ahead of print:

http://journals.humankinetics.com/ssj-in-press/ssj-in-press/touchy-subject-a-foucauldian-analysis-ofcoachesrsquo-perceptions-of-adult-child-touch-in-youth-swimming

Andrzejewski, C.E., \& Davis, H. A. (2008). Human contact in the classroom: Exploring how teachers talk about and negotiate touching students. Teaching and Teacher Education, 24, 779-794.

Barker-Ruchti, N., \& Tinning, R. (2010). Foucault in leotards: Corporeal discipline in women's artistic gymnastics. Sociology of Sport Journal, 27, 229-250.

Beck, U. (1992). Risk society: Towards a new modernity. London: Sage.

Beck, U. (2002). The terrorist threat: World risk society revisited. Theory, Culture and Society, 19, 39-55.

Brackenridge, C., Bringer, J. D., \& Bishopp, D. (2005). Managing cases of abuse in sport. Child Abuse Review, 14, 259-274.

British Swimming (n.d). Teaching in the water and the handing of children. Available at: www.swimming.org/assets/uploads/library/Teaching_in_the_water_handling_pupils.pdf. Accessed 19/6/13.

Chapman, G. E. (1997). Making weight: Lightweight rowing, technologies of power and technologies of the self. Sociology of Sport Journal, 14, 205-223.

Child Protection in Sport Unit (CPSU). (2003) Standards for safeguarding and protecting children in sport. Leicester: CPSU.

Cushion, C. (2007). Modelling the complexity of the coaching process: A response to commentaries. International Journal of Sports Science and Coaching, 2, 427-433. 
Lang, M. (2015) Touchy Subject: A Foucauldian Analysis of Coaches' Perceptions of Adult-Child Touch in Youth Swimming. Sociology of Sport Journal. 5. Available online ahead of print:

http://journals.humankinetics.com/ssj-in-press/ssj-in-press/touchy-subject-a-foucauldian-analysis-ofcoachesrsquo-perceptions-of-adult-child-touch-in-youth-swimming

Denison, J., \& Scott-Thomas, D. (2011). Michel Foucault: Power and discourse - The 'loaded' language of coaching. In R. L. Jones, P. Potrac, C. Cushion, \& L. R. Ronglon (Eds.). The Sociology of Sports Coaching (pp. 27-39). London: Routledge.

Fasting, K. Brackenridge, C., \& Sundgot-Borgen, J. (2004). Prevalence of sexual harassment among Norwegian female elite athletes in relation to sport type. International Review for the Sociology of Sport, 39, 373-386.

Field, T. (2003). Touch. Cambridge, MA.: MIT Press.

Foucault, M. (1970). The order of things: An archaeology of the human sciences. London:

Tavistock.

Foucault, M. (1977a). Discipline and punish: The birth of the prison. London: Allen Lane.

Foucault, M. (1997b) Sexuality and solitude. In P. Rabinow (Ed.). Ethics, Subjectivity and Truth: Michel Foucault 1926-1984 (pp. 170-196). London: Penguin.

Foucault, M. (1978). The history of sexuality. Volume 1: The will to knowledge. New York: Pantheon.

Foucault, M. (1983). The subject and power. In H. L. Dreyfus \& P. Rabinow (Eds.). Michel Foucault: Beyond Structuralism and Hermeneutics (pp. 208-226). Chicago: Chicago University Press.

Foucault, M. (1984). The history of sexuality. Volume 2: The use of pleasure. London: Random House. 
Lang, M. (2015) Touchy Subject: A Foucauldian Analysis of Coaches' Perceptions of Adult-Child Touch in Youth Swimming. Sociology of Sport Journal. 5. Available online ahead of print:

http://journals.humankinetics.com/ssj-in-press/ssj-in-press/touchy-subject-a-foucauldian-analysis-ofcoachesrsquo-perceptions-of-adult-child-touch-in-youth-swimming

Foucault, M. (1988a). Truth, power, self. In L. H. Martin, H. Gutman \& P. H. Hutton (Eds.).

Technologies of the Self: A Seminar with Michel Foucault (pp. 1-21). Amherst, MA.:

University of Massachusetts Press.

Foucault, M. (1988b). Technologies of the self. In L. H. Martin, H. Gutman \& P. H. Hutton

(Eds.). Technologies of the Self: A Seminar with Michel Foucault (pp. 16-49). Amherst, MA.:

University of Massachusetts Press.

Furedi, F. (2001). Paranoid parenting: Why ignoring the experts may be best for your child ( $1^{\text {st }}$ ed.). London: Allen Lane.

Goetz, J., \& LeCompte, M. (1984). Ethnography and qualitative design in educational research. New York: Academic Press.

Gray, D., \& Watt, P. (2013). Giving victims a voice: Joint report into sexual allegations made against Jimmy Savile. London: Metropolitan Police Service/NSPCC. Available at: http://www.nspcc.org.uk/news-and-views/our-news/child-protection-news/13-01-11-yewtreereport/yewtree-report-pdf_wdf93652.pdf. Accessed on 19/6/13.

Grenfell, C. C., \& Rinehart, R. E. (2003). Skating on thin ice: Human rights in youth figure skating. International Review for the Sociology of Sport, 38, 79-97.

Hewitt, D. (2010). Positive reasons for giving and making available physical contact to students. Intensive Interaction [online]. Available at: www.intensiveinteraction.co.uk/blog/user-contributions/positive-rea-to-students/00048.html. Accessed on 14/1/13. 
Lang, M. (2015) Touchy Subject: A Foucauldian Analysis of Coaches' Perceptions of Adult-Child Touch in Youth Swimming. Sociology of Sport Journal. 5. Available online ahead of print:

http://journals.humankinetics.com/ssj-in-press/ssj-in-press/touchy-subject-a-foucauldian-analysis-of-

coachesrsquo-perceptions-of-adult-child-touch-in-youth-swimming

Johns, D. P., \& Johns, J. S. (2000). Surveillance, subjectivism and technologies of power: An analysis of the discursive practice of high-performance sport. International Review for the Sociology of Sport, 35, 219-234.

Johnson, B., \& Christensen, L. (2004). Educational research: Quantitative, qualitative and mixed approaches. Boston: Pearson Education.

Jones, A. (2004). Social anxiety, sex, surveillance and the 'safe' teacher. British Journal of Sociology of Education, 25, 53-66.

Jones, R. L. (2009). Coaching as caring (the smiling gallery): Accessing hidden knowledge. Physical Education and Sport Pedagogy, 14, 377-390.

Jones, R. L., Bailey, J., \& Santos, S. (2013). Coaching, caring and the politics of touch: A visual exploration. Sport, Education and Society. doi:10.1080/13573322.2013.769945.

Jowett, S. (2005). The coach-athlete partnership. The Psychologist, 18, 412-415.

Jowett, S., \& Cramer, D. (2010). The prediction of young athletes' physical self from perceptions of relationships with parents and coaches. Psychology of Sport and Exercise, 11, 140-147.

Kidman, L., \& Lombardo, B. J. (Eds.). (2010). Athlete-centred coaching: Developing decision makers. Worcester: IPC.

Kneidinger, L. M., Maple, T. L., Tross, S. A. (2001). Touching behaviour in sport: Functional components, analysis of sex differences and ethiological considerations. Journal of NonVerbal Behavior, 25, 43-62. 
Lang, M. (2015) Touchy Subject: A Foucauldian Analysis of Coaches' Perceptions of Adult-Child Touch in Youth Swimming. Sociology of Sport Journal. 5. Available online ahead of print:

http://journals.humankinetics.com/ssj-in-press/ssj-in-press/touchy-subject-a-foucauldian-analysis-ofcoachesrsquo-perceptions-of-adult-child-touch-in-youth-swimming

Lang, M. (2009). Swimming in the Panopticon: An ethnographic study of good practice and child protection in competitive youth swimming, unpublished $\mathrm{PhD}$ thesis, Leeds Metropolitan University.

Lang, M. (2010). Surveillance and conformity in competitive youth swimming. Sport, Education and Society, 15, 19-37.

Lincoln, Y. S., \& Guba, E (1985). Naturalistic enquiry. Beverley Hills, CA.: Sage.

Markula, P. (1995). Firm but shapely, fit but sexy, strong but thin: The postmodern aerobicising female bodies. Sociology of Sport Journal, 12, 424-453.

Markula, P. (2003). The technologies of the self: Sport, feminism and Foucault. Sociology of Sport Journal, 20, 87-107.

Markula, P. (2004). 'Turning into oneself': Foucault's technologies of the self and mindful fitness. Sociology of Sport Journal, 21, 302-321.

Markula, P., \& Pringle, R. (2006). Foucault, sport and exercise: Power, knowledge and transforming the self. London: Routledge.

Marshall K., \& Mellon, M. (2011). Crowding out wisdom: The mechanisation of adult-child relationships. In L. Bondi, D. Carr, C. Clark \& C. Clegg (Eds.). Towards professional wisdom: Practical deliberation in the people professions (pp. 187-204). Farnham: Ashgate.

Martin, S. B., Dale, G. A., \& Jackson, A. W. (2001). Youth coaching preferences of adolescent athletes and their parents. Journal of Sport Behavior, 24, 197-212. 
Lang, M. (2015) Touchy Subject: A Foucauldian Analysis of Coaches' Perceptions of Adult-Child Touch in Youth Swimming. Sociology of Sport Journal. 5. Available online ahead of print:

http://journals.humankinetics.com/ssj-in-press/ssj-in-press/touchy-subject-a-foucauldian-analysis-of-

coachesrsquo-perceptions-of-adult-child-touch-in-youth-swimming

Maykut, P., \& Morehouse, R. (1994). Beginning qualitative researchers: A philosophical and practical guide. Washington, DC: Falmer.

McAlinden, A.-M. (2006). 'Setting ‘em up': Personal, familial and institutional grooming in the sexual abuse of children. Social and Legal Studies, 15, 339-362.

McNeill, P. (1988). Doing Social Research. Basingstoke: Macmillan.

McWilliam, E., \& Jones, A. (2005). An unprotected species? On teachers as risky subjects.

British Educational Research Journal, 31, 109-120.

McWilliam, E., \& Sachs, J. (2004). Towards the victimless school: Professionalism and probity in teaching. Educational Research for Policy and Practice, 3, 17-30.

Murray, C., \& Malmgren, K. (2005). Implementing a teacher-student relationship programme in a high-poverty urban school: Effects on social, emotional and academic adjustment and lessons learned. Journal of School Psychology, 43, 137-152.

Pain, R. (2006). Paranoid parenting? Rematerializing risk and fear for children. Social and Cultural Geography, 7, 221-243.

Pearce, C. (2010). The life of suggestions. Qualitative Inquiry, 16, 902-908.

Piper, H., Taylor, B., \& Garrett, D. (2012). Sports coaching in a risk society: No touch, no trust! Sport, Education and Society, 17, 1-15.

Piper, H., Powell, J., \& Smith, H. (2006). Parents, professionals and paranoia: The touching of children in a culture of fear. Journal of Social Work, 6, 151-167. 
Lang, M. (2015) Touchy Subject: A Foucauldian Analysis of Coaches' Perceptions of Adult-Child Touch in Youth Swimming. Sociology of Sport Journal. 5. Available online ahead of print:

http://journals.humankinetics.com/ssj-in-press/ssj-in-press/touchy-subject-a-foucauldian-analysis-ofcoachesrsquo-perceptions-of-adult-child-touch-in-youth-swimming

Piper, H., \& Stronach, I. (2008). Don't touch! The educational story of a panic. London: Routledge.

Potrac, P., Jones, R., \& Armour, K. (2002). 'It's all about getting respect': The coaching behaviours of an expert English soccer coach. Sport, Education and Society, 7, 183-202.

Rail, G., \& Harvey, J. (1995). Body at work: Michel Foucault and the sociology of sport. Sociology of Sport Journal, 12, 164-175.

Shogan, D. (1999). The making of high-performance athletes: Discipline, diversity and ethics. Toronto: University of Toronto Press.

Sikes, P., \& Piper, H. (2011). Researching allegations of sexual misconduct in schools: The need for a narrative approach. Sexuality Research and Social Practice, 8, 294-303.

Sparkes, A. C. (1989). Paradigmatic confusion and the evasions of critical issues in naturalistic research. Journal of Teaching in Physical Education, 8, 131-151.

Sparkes, A. C. (2000). Illness, premature termination and the loss of self: A biographical study of an elite athlete. In R. Jones \& K. Armour (Eds.). Sociology of sport: Theory and practice (pp. 13-32). London: Addison Wiley Longman.

Sport England (2013). Active people survey 7. Available at: www.sportengland.org/research/who-plays-sport/by-sport/who-plays-sport. Accessed on 19/6/13.

Sports Coach UK (2011). Sports coaching in the UK 3: A statistical analysis of coaching and coaches in the UK. Leeds: Sports Coach UK. 
Lang, M. (2015) Touchy Subject: A Foucauldian Analysis of Coaches' Perceptions of Adult-Child Touch in Youth Swimming. Sociology of Sport Journal. 5. Available online ahead of print:

http://journals.humankinetics.com/ssj-in-press/ssj-in-press/touchy-subject-a-foucauldian-analysis-ofcoachesrsquo-perceptions-of-adult-child-touch-in-youth-swimming

Svender, J., Larsson, H., \& Redelius, K. (2012). Promoting girls' participation in sports:

Discursive constructions of girls in a sports initiative. Sport, Education and Society, 17, 463478.

Ungar, S. (2001). Moral panic versus the risk society: The implications of the changing sites of social anxiety. British Journal of Sociology, 52, 271-291.

Williams, E. (2004). False accusations. Times Educational Supplement. 20 February, 11-14.

Woods, P. (1986). Inside schools: Ethnography in educational research. London: Routledge \& Kegan Paul.

Willis, P. (1980). Notes on method. In S. Hall (Ed.). Culture, Media and Language (pp. 142156). London: Hutchinson. 